coal, this temperature lies between $350^{\circ}$ and $450^{\circ} \mathrm{C}$. $\mathrm{X}$-The residue at $350^{\circ}$ has a calorific value of I 2,790 B. t. u., which is an increase of 22.8 per cent over the coal as mined, and of 14.7 per cent over the dry coal.

\section{HARDENING EFFECTS OF VARIOUS ELEMENTS UPON LEAD}

\section{By Car1 O. Thieme}

Michigan Smeiting and Refining Company, Detrott, Michtaan Received November 22, 1919

During the war, the high price and the threatened famine in tin, due to labor conditions, shortage of ship bottoms, and possibly to the submarine warfare, caused the manufacturers of this country to search and experiment with other metals and alloys that could be used in place of those containing tin. Of course, the greater portion of this work was done on tin-base bearing metals, but the conservation of tin was aided by the substitution of other metal for tin, in brass and bronze alloys.

It is quite well known that the composition of gun metal, 88-10-0-2, was modified to 88-8-0-4, with results that were just as satisfactory. In other cases, tin was entirely omitted from bronzes, and aluminum substituted, producing alloys that were decidedly superior to the tin bronze, with regard to physical properties, although as a general rule difficulty was encountered in manufacturing aluminum bronze castings. Commercial manganese bronze, which is essentially a copper-zinc-iron alloy, found a greater use, and the use of yellow brass mixtures in general became more popular. The tin content of brass mixtures containing the four elements, copper, tin, lead and zinc, in many instances was decreased, and one or two of the other show the hardening effect of the various elements upon lead.

The hardening effect of the elements will be taken up in the order in which they appear in the accompanying table.

CALCIUM-Lead may be hardened by the addition of about one per cent of calcium. ${ }^{1}$ It then has a Brinell hardness of $I_{5}$, and quite a metallic ring. The alloy does not long retain a luster, and in a short time darkens a great deal. It shows numerous small blisters appearing on the surface of the metal, which will chip off, giving the metal a sort of pocked appearance. We believe that this alloy, upon remelting several times, loses its hardness, due, undoubtedly, to the oxidation and consequent skimming off of the calcium, together with the lead oxide. An admixture of barium and calcium is sometimes added as the hardening agent.

SODIUM-Sodium added to lead hardens it considerably, giving a Brinell hardness of approximately 5 to 6 . This alloy also loses its hardness after several remelts. It is believed by some that the hardening constituent in an alloy of this kind is a substance having the formula $\mathrm{Na}_{2} \mathrm{~Pb}_{5}{ }^{2}$ The eutectic of leadsodium alloys is 2.5 per cent sodium, and 97.5 per cent lead. As the sodium is increased, the Brinell hardness gradually increases until at 0.8 per cent (the maximum amount of sodium dissolved by lead) the Brinell hardness is 8 . From 0.8 to 2.5 per cent the hardness does not increase, but falls off with sodium values higher than 2.5 per cent.

ARSENIC-Arsenic hardens lead and increases the fusibility of the alloy. The quantity of arsenic added is generally under one per cent, and probably not more than 0.5 per cent. On account of the increased fusibility, this metal is used to advantage in making lead

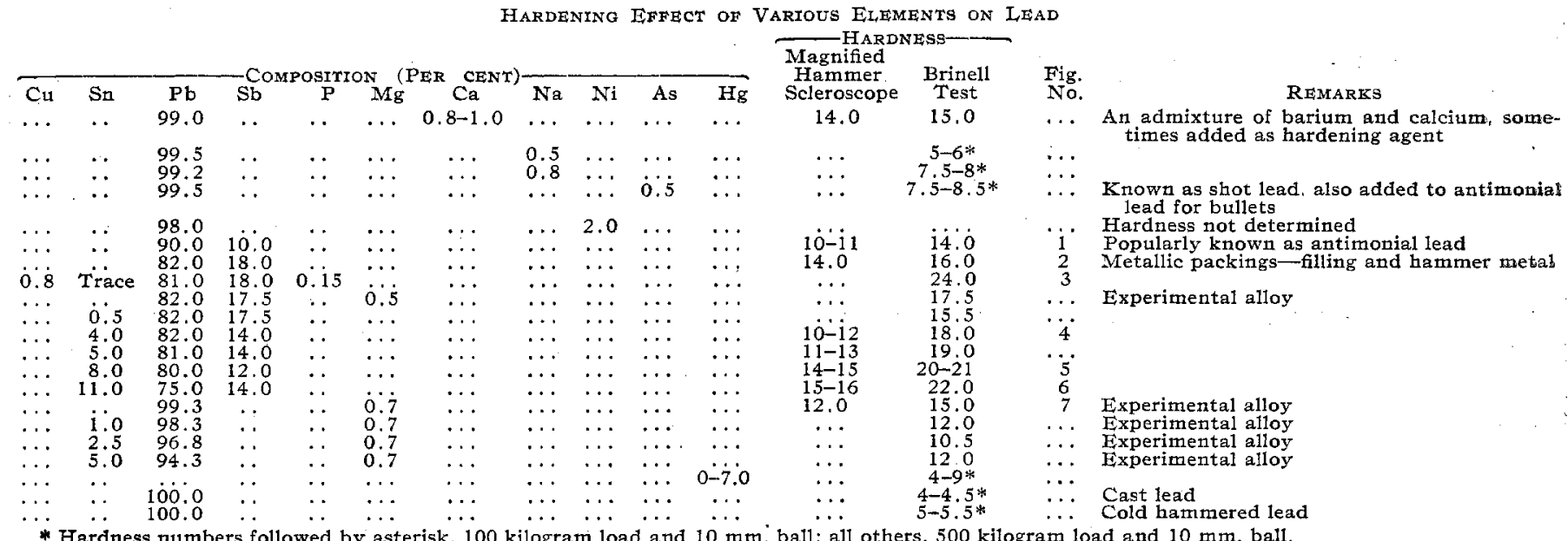

* Hardness numbers followed by asterisk, 100 kilogram load and $10 \mathrm{~mm}$. ball; all others, $500 \mathrm{kilogram}$ load and $10 \mathrm{~mm}$. ball.

metals increased, producing alloys that were cheaper and gave just as satisfactory results for the purposes for which they were used.

As stated above, the conservation of tin was due largely to the use of lead-base and leaded white metals. It is not my intent to enter into a discussion of the values of lead-base bearing metals at this time, for there are many articles, pro and con, published on this subject, but to present the following data which will shot, for the time taken in solidifying gives the metal better opportunity to form a spherical drop.

NICKEL-Nickel, when added to lead, has a decided hardening effect, but on account of the great difference in their melting points, the use of this alloy is rather out of the question. The component metals must be

1 Chem. \& Met. Eng., Sept. 28 (1918), p. 253.

2C. F. Desch, "Metallography," 2nd Ed., 1913; C. H. Mathewson, Z. anorg. Chem., $50(1906), 171$. 
melted separately, and mixed in the molten condition. An alloy of 2 per cent nickel and 98 per cent lead has a good appearance and is quite resonant.

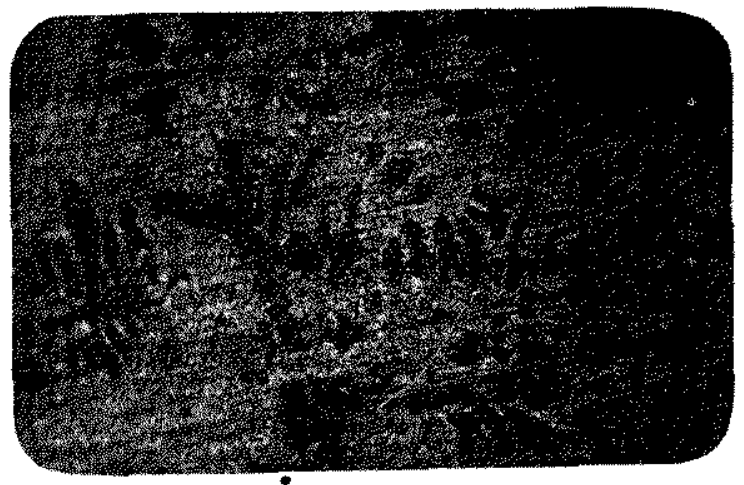

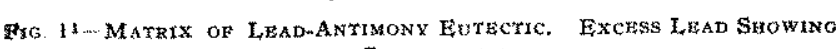
AS CEYSTALITIES

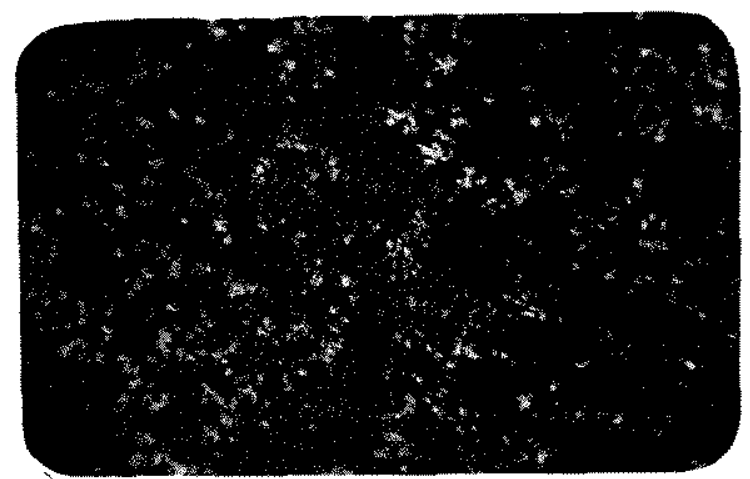

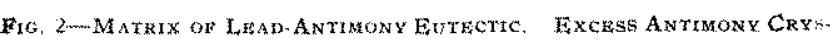
TALS DISTREBTED UNMORMLY THROWGHOUT THE SECTION

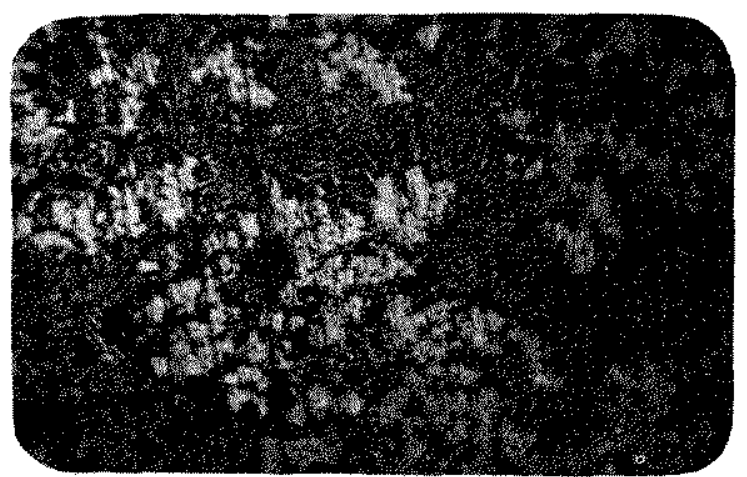

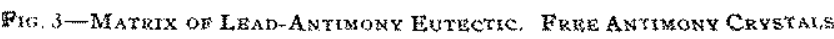

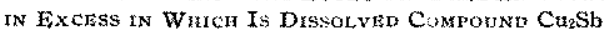

ANTrony-Antimony has long been used to harden lead, and has a wide use commercially as filling metal and hammer metal, and in some instances as an antifriction metal. When the alloy contains more than 18 or 20 per cent antimony, it becomes too brittle for practical use. The hardness is proportional to the antimony content, and the increase is due to the formation of a eutectic having the composition 87 per cent lead and $x 3$ per cent antimony. The hardness is increased approximately one number (Brinell) for each

All photonicrographs shown here are taken at 100 magnifiations and are etclsed with a dilute solution of nitric acid in ethyl alcohol. per cent of antimony added up to the eutectic point, when the proportionate increase of hardness in the alloy does not hold true. The hardness of a mixture of ro per cent antimony and $9 \circ$ per cent lead is approximately ${ }_{4}$ Brinell, which corresponds to the calcium-lead alloy (Fig. I).

An alloy of antimony and lead, of the composition 87 per cent lead and 13 per cent antimony, shows neither lead nor antimony in excess, and is entirely composed of the eutectic. When the antimony content is increased to 18 per cent the alloy shows a hardness of 16 Brinell. The grain of this metal, however, varies greatly and is controlled only with considerable difficulty by pouring into a water-cooled mold. In order to prevent segregation, it is necessary to pour this metal as near the melting point as possible. The mixture is quite resonant, and, unlike the calcium and the sodium hardened lead alloys, does not lose its hardness upon remelting. It is brittle and fractures easily. Fig. 2 shows structure of an alloy of the composition $82-18$.

The addition of one per cent phosphor copper to the alloy just mentioned has a decided hardening effect. showing a Brinell hardness of 24.0. However, this alloy is more brittle than the antimony-lead mixture, and loses its luster more quickly. It is extremely hard to cast, as it pours very sluggishly, and segregation is bound to occur in spite of all precautions. This is explained by the fact that, in order to cast a sound bar, the temperature must be raised to increase the fluidity, and flotation of the antimony crystals results. The grain is finer than the $82-18$ antimonylead mixture, thereby offering an explanation for the increased hardness, and a fracture of the metal shows a finely crystalline grain, similar in color to gray iron. Fig. 3 illustrates the segregation of free antimony.

Magnesium hardens the alloy of antimony and lead, although not to as great extent as the addition of one per cent phosphor copper. Onewhalf per cent of magnesium added to this alloy produces a metal having a hardness of 77.5 . It is almost silvery white when first cast, but the luster slowly disappears and the alloy darkens.

One-half per cent of tin does not noticeably alter the properties of this alloy, although a series of hardness tests shows a slight decrease to 15.5 Brinell. A microscopical examination reveals the formation of a few imperfectly formed tin-antimony cubes, very unevenly distributed throughout the section. These crystals are absent in the other alloys. As the tin content is increased to 4 per cent, and the antimony decreased proportionately, the resultant alloy gives a Brinell hardness of 17.5 to 18.0 (Fig. 4). The addition of 5 per cent tin produces an alloy of 19.0 Brinell hardness. On increasing the tin content still further to 8 per cent, the structure of the metal is changed, and as the composition nears the hypothetical ternary tin-lead-antimony eutectic (none formed) we find a fine grained alloy. This is an ideal alloy of the three metals, due to the fact that it retains its luster better than the majority of lead-base metals of this series, and readily takes a high polish. Its hardness is 20.0 (Fig. 5). 


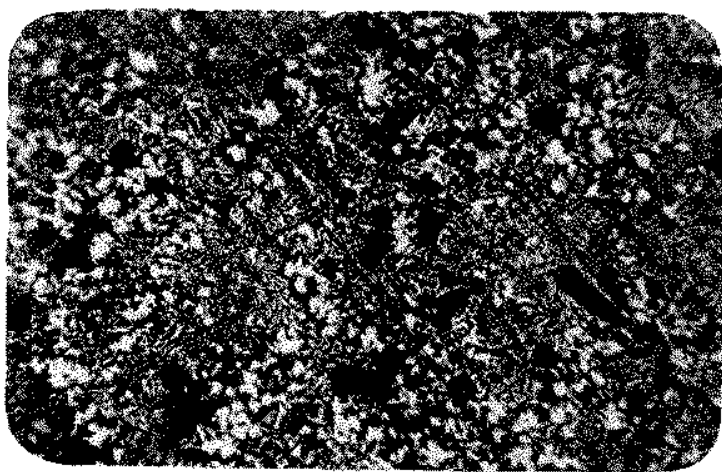

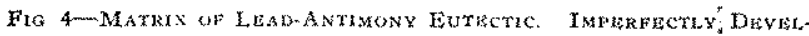
open Tin-antrmonx Gamma Constituent and a Small Pegcintage OF EXESSS LTAD

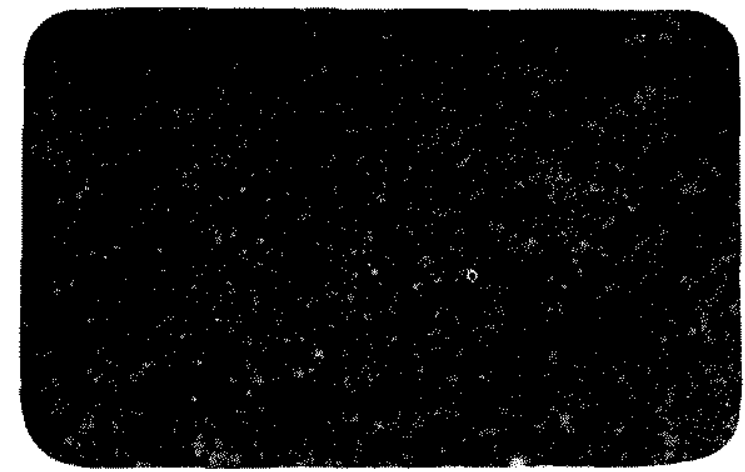

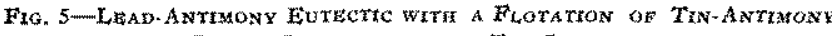
Gamma Constrought and Tin Crystaks

An I per cent tin alloy of the same series gives a hardness of $2 \mathrm{r} .5$ to 22.0 Brinell (Fig. 6). It will be noticed in the tin-lead-antimony alloys that, as the tin is increased $I$ per cent, the hardness is increased half a number in each instance. Most bearing metals of the lead-base series should not contain more than ro per cent tin unless the antimony is increased proportionately. However, the alloy then becomes brittle, as in the case of the binary alloy of lead and antimony. Above ro per cent tin, the addition of tin to leadantimony alloys does not exert as great a hardening effect as is true when smaller percentages are added.

MAGNESIUM-Magnesium ${ }^{2}$ hardens lead when added in small amounts, usually one per cent or under. An alloy containing one-half per cent magnesium has a Brinell hardness of $\mathbf{3} .0$. Difficulty is encountered, however, in alloying these metals. The alloys were made by introducing small pieces of magnesium into the molten lead until the former gradually melted and dissolved. After the magnesium is alloyed with the lead it does not oxidize rapidly, and, therefore, retains its luster and its hardness upon remelting. The writer believes the hardening constituent in this alloy to be a substance having the composition $\mathrm{Mg}_{2} \mathrm{~Pb}$, which Kurnakoff and Stepanoff found to solidify at $55 \mathrm{I}^{\circ} \mathrm{C}^{2}$ The photomicrograph (Fig. 7), although considerably scratched, illustrates the formation of this material. 435

'Metall u. Ers, n. s., 7 (1919), 79; abstracted in J. Inst. Metals, 21 (1919),

Grube, Z. anorg. Chem, 44 (1905), 117; 16 (1905), 177

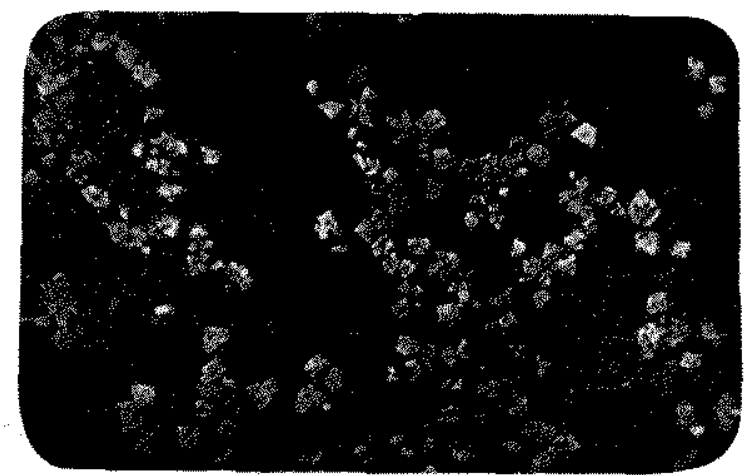

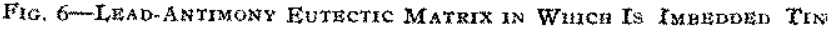
Antrmonx Gamma Constiturint

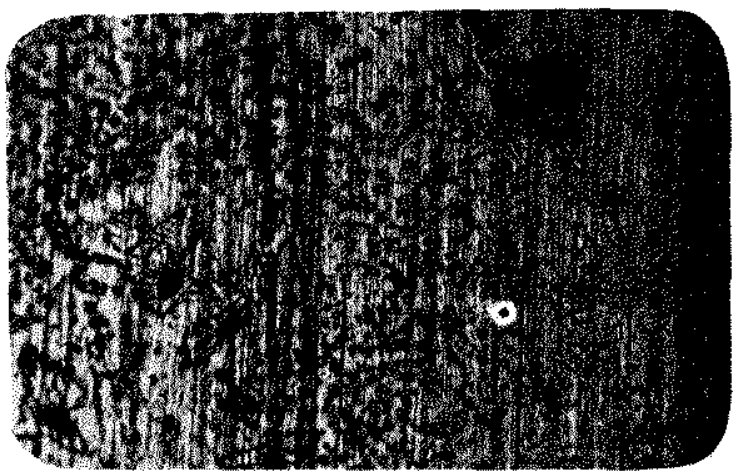

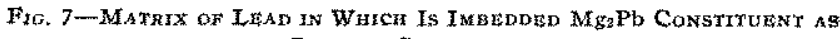
Primaky CRXstaleztris

The addition of one per cent tin to this mixture softens the alloy, giving a Brinell hardness of 12.0 , while 2.5 per cent tin lowers it still further to 10.5 . Between 2.5 and 5 per cent tin there is a limit to the falling hardness, and a mixture containing 5 per cent tin again raises the hardness to 12.0. An alloy of this composition would be rather expensive, as com. pared with the alloys previously mentioned, which give a greater hardness at a lower cost.

MERCURY - A recent investigation of lead alloys, with mercury, sodium, and tin, by J. Goebel, ${ }^{1}$ shows that mercury, when added to lead, increases its hardness from 4 to 9 Brinell. Any amount of mercury up to a maximum of 7 per cent increases the hardness proportionately.

The hatuness of cast lead and cold hammered lead is given at the foot of the table, to allow of comparison in degree of hardness.

\section{THE SOLUBILITY OF MONO- AND DIAMMONIUM PHOSPHATE}

By G. H. Buchanan and G. B. Winner

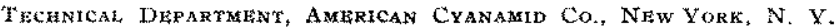
Received November 29,1919

In connection with certain experimental work recently carried on in this laboratory, more definite information than could be found in the literature was required concerning the solubility of the two commercial

I Z. Ver, deul. Ing., May 10, 1919; abstracted in Turs JourNat, 11 (119), 1065. 